\title{
Regulation of Plasma Amino Acid Levels by Perfusion of Hindquarters of Rats
}

\author{
Motoni KADOwaKI, Tadashi NoguchI, and Hiroshi NAITO ${ }^{1}$ \\ Department of Agricultural Chemistry, Faculty of Agriculture, \\ The University of Tokyo, Tokyo 113, Japan
}

(Received October 13, 1983)

\begin{abstract}
Summary To clarify the role of skeletal muscle in the regulation of plasma amino acid levels, we investigated the response of skeletal muscle to changes in plasma amino acid levels using the perfusion technique of rat hindquarters. The hindquarters of overnight-fasted rats were perfused with a medium containing no amino acids $(0 \times)$ and amino acids with plasma levels simulating normal $(1 \times)$ or 5 times the normal levels $(5 \times)$. Each amino acid level in the perfusate changed in various ways during a $2 \mathrm{~h}$ perfusion. The characteristics of amino acid flows in response to the changes in their perfusate levels were divided into four groups as follows: the amino acids which are always taken up irrespective of their plasma levels: glutamate and aspartate; those which are always released: alanine, glutamine and glycine; those which are taken up or released depending on their plasma levels: valine, leucine, isoleucine, serine and (threonine); and those which are released at lower, but neither taken up nor released, at higher plasma levels: tyrosine, phenylalanine, tryptophan, histidine, methionine, asparagine, arginine, lysine and proline. Comparing these results with the data of liver perfusion (Bloxam, D. L. (1971): Br. J. Nutr., 26, 393-422), we assumed that skeletal muscle plays a role complementary to liver in the regulation of plasma amino acid levels.
\end{abstract}

Key Words plasma amino acids, branched-chain amino acids, skeletal muscle, hindquarter perfusion

Plasma amino acid levels are regulated by many nutritional and hormonal factors and reflect the integrated features of the metabolism of many organs in the body (1). Liver and skeletal muscle are known to be the two major organs which regulate plasma amino acid levels. Liver takes up, metabolizes and releases most amino acids except those of the branched-chain type. On the other hand, skeletal muscle has been shown to be the main organ which metabolizes the branched-chain amino acids. Moreover, on starvation, skeletal muscle synthesizes and releases alanine and glutamine into the circulation, whereas liver takes up alanine for

1 門脇基二, 野口 忠, 内藤 博 
gluconeogenesis. Most of the knowledge on inter-organ amino acid flow has been obtained by the arterio-venous difference method. However, this method is not appropriate to elucidate quantitatively the metabolic response of the organ to changes in plasma amino acid levels. In 1971, Bloxam applied the liver perfusion system to investigate the role of liver in the regulation of plasma amino acid levels (2). He showed that liver always releases branched-chain amino acids and always takes up glutamate, aspartate, alanine, serine and arginine irrespective of their plasma levels. On the other hand, this organ regulates the levels of other amino acids in response to their plasma levels. These findings suggested that skeletal muscle might play a role complementary to that of liver in regulating plasma amino acid levels. However, little work has been reported to date on the response of skeletal muscle to changes in plasma amino acid levels(3). In the present study, we investigated the response of skeletal muscle to changes in plasma amino acid levels using the technique of perfusion of rat hindquarters. The results clearly show the complementary role of skeletal muscle to that of liver in the regulation of plasma amino acid levels.

\section{MATERIALS AND METHODS}

Animals. Male Wistar rats (Shizuoka Agricultural Co-operative Association for Laboratory Animals, Hamamatsu, Japan) were fed on a commercial stock diet (Type MF, Oriental Yeast Co., Ltd., Tokyo) ad libitum and had free access to water. Animals weighing 160-180 g were used for the perfusion experiments after overnight fasting.

Hindquarter perfusion. Rat hindquarters were perfused using an apparatus described by Yagasaki and Kametaka(4). Most of the operating procedures followed Ruderman et al.(5), but some were modified because male instead of female rats were used in the present experiments. The rats were anesthetized with sodium pentobarbital $(50 \mathrm{mg} / \mathrm{kg}$ BW). After midline abdominal incision, the following structures were ligated: the internal spermatic vessels, coeliac artery, superior and inferior mesenteric arteries, portal vein, pylorus and rectum, and the whole intestine was excised. Tight ligatures were then placed on the hypogastric and pudic epigastric trunks and around the internal spermatic vessels, and the testes were excised. The iliolumbar and renal vessels were also ligated securely. After carefully separating the aorta and vena cava between the left renal and iliolumbar vessels, two ligatures were placed loosely around each vessel. Immediately after the halting of the aortic bloodstream above the left renal vessels using a clip, a polyethylene cannula for the aorta ( $1 \mathrm{~mm}$ in diameter) filled with heparin solution was inserted from a point of the ligature to near the aortic bifurcation, tightly ligated and the perfusate was allowed to flow through. Another cannula for the vena cava ( $2 \mathrm{~mm}$ in diameter) was inserted into the point between the right renal and iliolumbar vessels. Finally, a tight ligature was placed around both vessels above the position of cannulation. During this operation, the cessation of oxygen supply to the 
hindquarters was less than 2 or $3 \mathrm{~min}$. The whole procedure required about $25 \mathrm{~min}$.

The perfusion medium, prepared according to Jefferson (6), comprised KrebsHenseleit bicarbonate buffer ( $\mathrm{pH} 7.4$ ) containing $33 \%$ fresh bovine erythrocytes at a hematocrit of approx. 25, 3\% bovine serum albumin, $10 \mathrm{~mm}$ glucose and amino acids. When the amino acids were added to the perfusate, the levels were made up to simulate normal rat plasma levels $(1 \times)$ as follows: Asp, 13.8; Thr, 173.5; Ser, 131.1; Glu, 96.2; Gln, 684.4; Gly, 138.0; Ala, 507.2; Val, 171.5; Met, 40.2; Ile, 59.5; Leu, 103.9; Tyr, 132.5; Phe, 56.0; Trp, 48.8; Lys, 643.8; His, 74.2; Arg, 87.6; Asn, 79.0; Pro, 182.7 (nmol $/ \mathrm{ml}$ perfusate), or added at five times those amounts $(5 \times)$. When it was necessary, bovine insulin $(25 \mathrm{mU} / \mathrm{ml}$ perfusate) was included in the medium. The perfusate flowed through at the rate of $8 \mathrm{ml} / \mathrm{min}$ and was oxygenated with a gas mixture of $95 \% \mathrm{O}_{2}-5 \% \mathrm{CO}_{2}(250-300 \mathrm{ml} / \mathrm{min})$ throughout the perfusion period. The medium prepared totalled $150 \mathrm{ml}$, and the initial $20 \mathrm{ml}$ passing through the tissues was discarded, the remainder then being recirculated for $2 \mathrm{~h}$. The perfusate volume at the end of perfusion was approx. $110 \mathrm{ml}$.

Analytical procedures. Immediately after the end of perfusion, the perfusate samples were centrifuged at $3,000 \mathrm{rpm}$ for $10 \mathrm{~min}$ to remove the erythrocytes and the supernatant was stored at $-20^{\circ} \mathrm{C}$ until analyses were done. In the present paper, hereafter, the term "perfusate" represents this supernatant. Muscle samples were rapidly removed from perfused hindquarters and frozen in liquid nitrogen and powdered for storage at $-80^{\circ} \mathrm{C}$. The perfusate was deproteinized in ice-cold $5 \%$ sulfosalicylic acid. After centrifugation at 3,000 rpm for $10 \mathrm{~min}$, the supernatant was adjusted to $\mathrm{pH} 2$ by $\mathrm{LiOH}$ and applied to a Hitachi 835 amino acid analyzer for free amino acid analysis. Muscle samples were homogenized with ice-cold $6 \%$ sulfosalicylic acid. After centrifugation at 3,000 rpm for $10 \mathrm{~min}$, they were treated as those of the perfusate.

The viability of perfused muscle preparations was checked by determining the contents of water, ATP and creatine phosphate and the rate of glucose uptake and lactate production. ATP and creatine phosphate were determined by the enzymic assay of Lamprecht et al.(7). Glucose in the perfusate was determined using a glucose oxidase-peroxidase test kit and lactate as described by Gutmann and Wahlefeld (8).

Perfused muscle mass. We estimated the perfused muscle mass for our hindquarter perfusion system. At the end of perfusion, hindquarters were stained by addition of Evans blue to the medium. The stained tissue was excised and weighed. After removal of the skin and fat pads, the remainder, muscle plus bone, was also weighed and dipped in $30 \% \mathrm{KOH}$ to dissolve the soft tissue. The latter was referred to as "muscle." The perfused muscle mass was expressed as percent of total body weight.

Extracellular space. To calculate the levels of free amino acids in the intracellular pool of perfused muscle, we measured the extracellular space (ECS) with $\left[{ }^{14} \mathrm{C}\right]$ sorbitol as a marker. After perfusing $\mathrm{D}-\left[U_{-}{ }^{14} \mathrm{C}\right]$ sorbitol $(2.5 \mathrm{mM})$ for $2 \mathrm{~h}$, the radioactivities in the perfusate and muscle were determined. ECS was calculated

Vol. 30, No. 2, 1984 
to be $0.15 \mathrm{ml} / \mathrm{g}$ wet weight.

Calculations. Calculations of the total amount of amino acid uptake from perfusate and those of the increase in the intracellular pool were derived from the following equations:

Total uptake from perfusate $(\mu \mathrm{mol})$

$$
=\left[\left(110 \times A_{0}+E \times B_{0}\right)-(110+E) \times A_{2}\right] \times V_{\mathrm{p}}
$$

Total increase in the intracellular pool $(\mu \mathrm{mol})=\left(C_{2}-C_{0}\right) \times I$

where $110(\mathrm{ml})$ is the mean perfusate volume during the perfusion, $E$ is the total extracellular space of perfused muscle, $A_{0}$ is the amino acid level in the perfusate plasma at $0 \mathrm{~h}, A_{2}$ is that at $2 \mathrm{~h}, B_{0}$ is the amino acid level in the normal plasma in vivo, $V_{\mathrm{p}}$ is the perfusate plasma volume $(=0.75), C_{0}$ is the intracellular amino acid level at $0 \mathrm{~h}, C_{2}$ is that at $2 \mathrm{~h}$, and $I$ is the total intracellular space of perfused muscle.

The statistical significance of the differences between mean values was analyzed by Student's $t$-test ( 9 ).

Materials. The erythrocytes were prepared from fresh bovine whole blood supplied by the Shibaura slaughterhouse in Tokyo. Bovine serum albumin (Cohn fraction V), L-lactic acid, and bovine insulin were purchased from Sigma Chemical Co. (St. Louis, U.S.A.). Enzymes and biochemicals used in ATP, creatine phosphate, glucose and lactate assays were obtained from Boehringer Mannheim (West Germany). D- $\left[U_{-}{ }^{14} \mathrm{C}\right]$ Sorbitol was purchased from Amersham (U.K.). Amino acids added in the perfusate were kindly offered by Ajinomoto Co. (Tokyo). All other chemicals were of reagent grade.

\section{RESULTS}

Since it was necessary to assess the viability of perfused hindquarter preparations in our system, several parameters for the assessment were determined and compared with those for muscle preparations in vivo (Table 1) or with the data of other investigators. Soon after an initial anoxia due to the halting of the bloodstream during the cannulation, hindquarters regained their normal coloration. The rates of glucose uptake and lactate production became constant after 20-30 min, and thereafter the rates were maintained throughout the following period. The normal preparations maintained a low level of lactate production, which was quite similar to that reported by Ruderman et al. $(2.4 \mu \mathrm{mol} / \mathrm{min} / 30 \mathrm{~g}$ muscle) (5). However, the responsiveness of glucose uptake to insulin was not as extensive as that shown by others $(5,10)$. At the end of $2 \mathrm{~h}$ of perfusion, the contents of water, ATP and creatine phosphate of the normal preparations were not significantly different from those of intact muscles before perfusion. Some preparations in which edema was evoked showed increases in water content, glucose uptake and lactate production. But the contents of ATP and creatine phosphate did not differ from those of in vivo and normal preparations. Ruderman et al. have claimed 
Table 1. Parameters of the viability of the perfused hindquarter preparation.

\begin{tabular}{lccccc}
\hline & $\begin{array}{c}\text { Water content } \\
(\% \text { wet wt. })\end{array}$ & $\begin{array}{c}\text { ATP content } \\
(\mu \mathrm{mol} / \mathrm{g})\end{array}$ & $\begin{array}{c}\text { Creatine-P } \\
\text { content } \\
(\mu \mathrm{mol} / \mathrm{g})\end{array}$ & $\begin{array}{c}\text { Glucose } \\
\text { uptake } \\
(\mu \mathrm{mol} / \mathrm{min} / 180 \mathrm{~g} \mathrm{BW})\end{array}$ & $\begin{array}{c}\text { Lactate } \\
\text { production }\end{array}$ \\
\hline $\begin{array}{l}\text { In vivo } \\
\text { Normal } \\
\quad \text { control } \\
\quad \text { insulin }\end{array}$ & $73.0 \pm 0.3(4)$ & $5.32 \pm 0.30(4)$ & $11.4 \pm 1.2(4)$ & - & - \\
Edema & $75.0 \pm 0.4(4)^{\mathrm{a}}$ & $5.56 \pm 0.22(3)$ & $15.7 \pm 0.6(3)^{\mathrm{a}}$ & $5.9 \pm 0.4(4)^{\mathrm{c}}$ & $3.2 \pm 0.3(4)^{\mathrm{b}}$ \\
\hline
\end{tabular}

Operating procedures of perfusion are described in MATERIALS AND METHODS. In the case of insulin addition, the hormone was added $25 \mathrm{mU} / \mathrm{ml}$ perfusate at the beginning of perfusion. The contents of water, ATP and creatine-P were determined in the hindquarters after $2 \mathrm{~h}$ perfusion. Glucose uptake and lactate production are the mean data of the perfusion period from $30 \mathrm{~min}$ to $2 \mathrm{~h}$. Values are means $\pm \mathrm{SE}$ for the numbers of observations in parentheses. A statistically significant difference is shown by superimposed letters as follows: ${ }^{\mathrm{a}} p<0.01$ vs. in vivo, ${ }^{\mathrm{b}} p<0.05 \mathrm{vs}$. control; ${ }^{\mathrm{c}} p<0.01 \mathrm{vs}$. control.

that a high rate of lactate production is as good a routine index of the inadequacy of perfusion as oxygen consumption(5). Our results also suggested that lactate production was the best of the parameters for normal perfusion among those we measured. Therefore, in later experiments, the viability of the preparations was mainly judged from general appearance and the rate of lactate production.

We measured the perfused muscle mass in our system for quantitative calculations. Our hindquarter preparations of normal perfusions consisted of "skin," "muscle" and "bone," 20.7 $\pm 1.0,68.8 \pm 0.9$ and $10.5 \pm 0.9 \%(n=5)$, respectively. The whole perfused hindquarters were $31.4 \pm 0.9 \%$ of body weight, and the muscle mass of these preparations was calculated to be $21.6 \pm 0.6 \%$ of the total body weight, which was a value a little higher than that of Ruderman et al. (5).

The response of skeletal muscle to the changes of amino acid levels in the perfusate is shown in Fig. 1. Rat hindquarters were perfused for $2 \mathrm{~h}$ with the medium containing no amino acids $(0 \times)$, those at normal plasma levels $(1 \times)$, or at 5 times the normal levels $(5 \times)$. Prior to these experiments, we had estimated the contribution of erythrocytes to the whole perfusate, and confirmed that erythrocytes did not affect significantly the amino acid levels of perfusate plasma (data not shown). In $0 \times$ and $1 \times$ groups, all of the amino acids except glutamate and aspartate linearly increased in the perfusate. On the other hand, glutamate and aspartate were rapidly taken up by muscle. This was also the case in the $5 \times$ group. When the initial levels of amino acids in the perfusate were raised to 5 times the normal plasma levels $(5 \times)$, the levels of all the amino acids fell in a similar manner during the first $30 \mathrm{~min}$ of perfusion. Thereafter, however, individual amino acid 


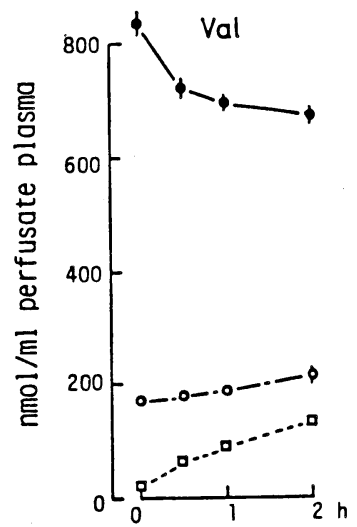

Leu

Ile
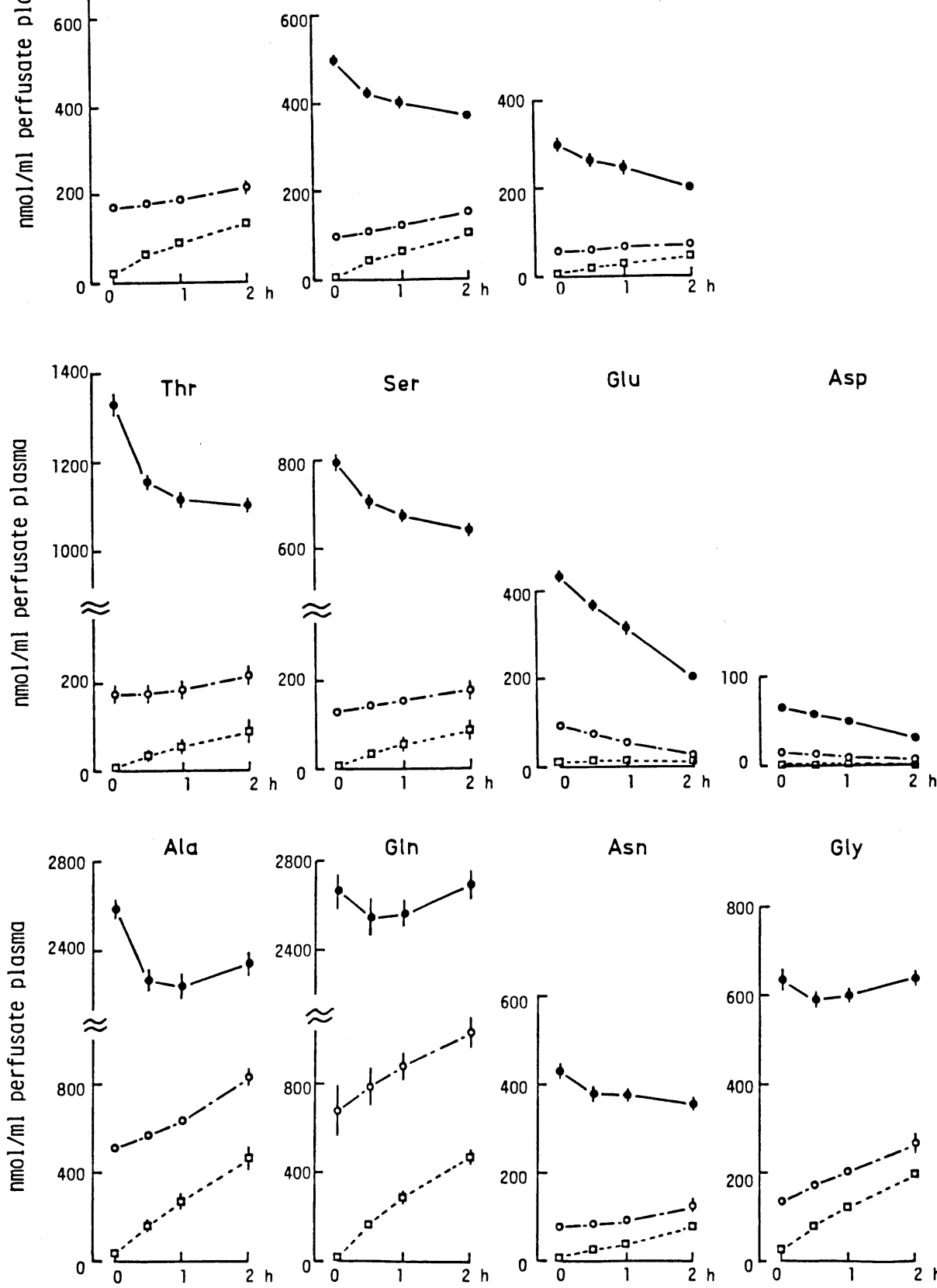

Asn

Gly
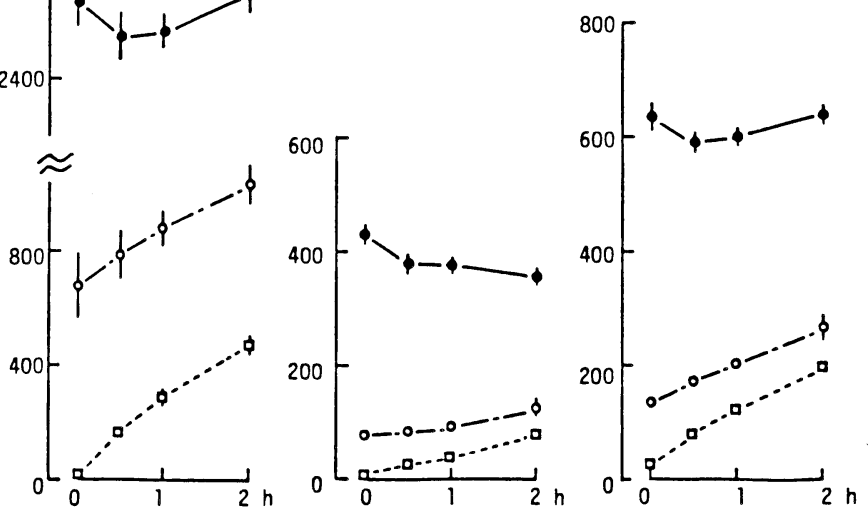

Fig. 1

J. Nutr. Sci. Vitaminol. 

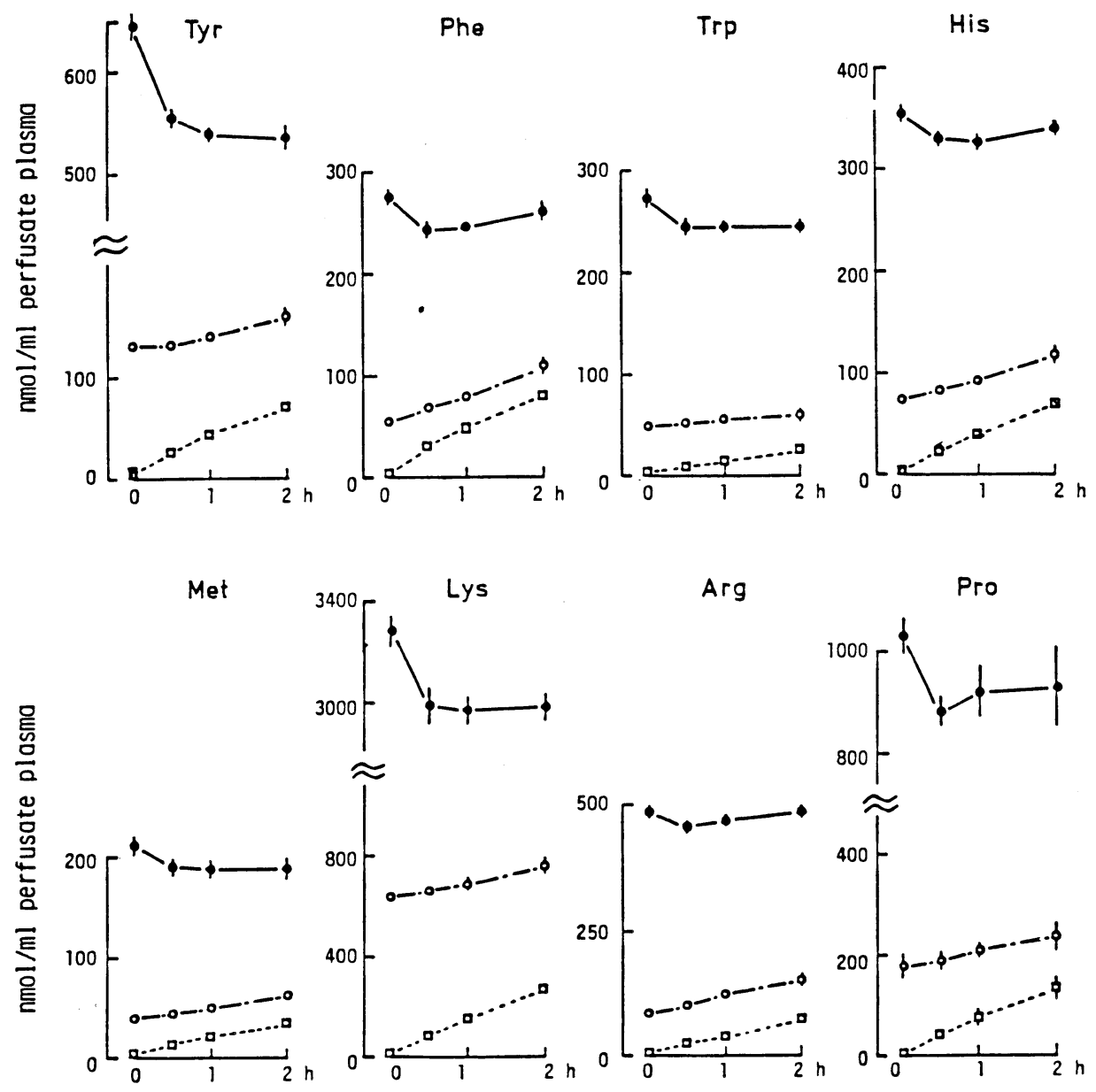

Fig. 1. Changes in amino acid levels in the perfusate during $2 \mathrm{~h}$ perfusion of rat hindquarters. Each point represents the mean $\pm \mathrm{SE}$ for five observations. The point without SE contains it within the circle or square. $\square--\square, 0 \times ; 0---\bigcirc, 1 \times$; -0, $5 \times$.

levels began to change in various ways. This initial decrease in amino acid levels would be due to non-specific uptake into muscle owing to a concentration gradient between the interior and exterior of the tissue. Therefore, the direction of flow of each amino acid in the $5 \times$ group was judged from the change in level between $30 \mathrm{~min}$ to $2 \mathrm{~h}$. The concentrations of valine, leucine, isoleucine, threonine, serine, glutamate and aspartate decreased, and those of alanine, glutamine and glycine tended to increase. The concentrations of the other nine amino acids did not change significantly. From these results, the amino acids were divided into four groups according to the characteristics of their flows to or from skeletal muscle in response 
to the changes in their perfusate levels, namely: those always taken up irrespective of their perfusate levels: glutamate and aspartate; those always released irrespective of their levels: alanine, glutamine and glycine; those taken up or released depending on their concentrations in the perfusate: valine, leucine, isoleucine, threonine and serine; those neither taken up nor released at higher plasma levels: tyrosine, phenylalanine, tryptophan, histidine, methionine, asparagine, arginine, lysine and proline.

The changes in intracellular amino acid levels of muscle during $2 \mathrm{~h}$ perfusion are shown in Table 2. Tyrosine and phenylalanine increased during the perfusion even when the perfusate did not contain amino acids $(0 \times)$. This suggested that the rate of protein degradation in the perfused muscle is faster than in the muscle in vivo. Glutamate and aspartate decreased in muscle as well as in the perfusate. These two amino acids are quickly taken up by muscle and metabolized rapidly in the tissue. The level of glycine in muscle did not change at all in all groups. Alanine and glutamine, which are known as the major carriers of nitrogen from skeletal muscle to other organs, responded in a similar manner in the perfusate to the changes in

Table 2. Intracellular amino acid levels of rat hindquarters after $2 \mathrm{~h}$ perfusion.

\begin{tabular}{|c|c|c|c|c|}
\hline & $\begin{array}{l}\text { Unperfused } \\
(\mathrm{mM})\end{array}$ & $\begin{array}{l}(0 \times) \\
(\mathrm{mm})\end{array}$ & $\begin{array}{l}(1 \times) \\
(\mathrm{mm})\end{array}$ & $\begin{array}{l}(5 \times) \\
(\mathrm{mM})\end{array}$ \\
\hline Asp & $0.31 \pm 0.02$ & $0.13 \pm 0.02^{b}$ & $0.18 \pm 0.03^{\mathrm{a}}$ & $0.23 \pm 0.02^{\mathrm{a}, \mathrm{d}}$ \\
\hline Thr & $0.66 \pm 0.02$ & $0.66 \pm 0.03$ & $0.78 \pm 0.02^{\mathrm{b}, \mathrm{d}}$ & $1.43 \pm 0.07^{\mathrm{b}, \mathrm{d}, \mathrm{f}}$ \\
\hline Ser & $1.07 \pm 0.02$ & $0.94 \pm 0.03^{b}$ & $1.04 \pm 0.07$ & $1.26 \pm 0.05^{\mathrm{b}, \mathrm{d}, \mathrm{f}}$ \\
\hline Asn & $0.41 \pm 0.03$ & $0.48 \pm 0.01$ & $0.52 \pm 0.01^{\mathrm{a}, \mathrm{c}}$ & $0.64 \pm 0.03^{b, d, f}$ \\
\hline Glu & $2.49 \pm 0.25$ & $0.79 \pm 0.06^{b}$ & $1.11 \pm 0.11^{\mathrm{b}, \mathrm{c}}$ & $1.12 \pm 0.11^{b, c}$ \\
\hline Gln & $3.80 \pm 0.16$ & $2.20 \pm 0.11^{b}$ & $2.78 \pm 0.16^{\mathrm{b}, \mathrm{d}}$ & $4.06 \pm 0.28^{\mathrm{d}, \mathrm{f}}$ \\
\hline Pro & $0.39 \pm 0.02$ & $0.47 \pm 0.02$ & $0.52 \pm 0.03^{\mathrm{b}}$ & $0.80 \pm 0.03^{\mathrm{b}, \mathrm{d}, \mathrm{f}}$ \\
\hline Gly & $5.10 \pm 0.21$ & $4.65 \pm 0.19$ & $5.15 \pm 0.21$ & $4.96 \pm 0.17$ \\
\hline Ala & $3.71 \pm 0.29$ & $5.52 \pm 0.22^{b}$ & $5.85 \pm 0.35^{b}$ & $6.67 \pm 0.18^{\mathrm{b}, \mathrm{d}, \mathrm{e}}$ \\
\hline Val & $0.27 \pm 0.01$ & $0.40 \pm 0.02^{b}$ & $0.38 \pm 0.02^{b}$ & $0.63 \pm 0.03^{b, d, f}$ \\
\hline Cys & $0.02 \pm 0.00$ & $0.01 \pm 0.00$ & $0.01 \pm 0.00$ & $0.01 \pm 0.00$ \\
\hline Met & $0.11 \pm 0.01$ & $0.12 \pm 0.01$ & $0.13 \pm 0.01$ & $0.20 \pm 0.01^{\mathrm{b}, \mathrm{d}, \mathrm{f}}$ \\
\hline Ile & $0.14 \pm 0.01$ & $0.25 \pm 0.02^{\mathrm{b}}$ & $0.21 \pm 0.02^{\mathrm{a}}$ & $0.27 \pm 0.02^{\mathrm{b}, \mathrm{e}}$ \\
\hline Leu & $0.21 \pm 0.01$ & $0.41 \pm 0.03^{\mathrm{b}}$ & $0.36 \pm 0.04^{\mathrm{b}}$ & $0.47 \pm 0.02^{b, c, f}$ \\
\hline Tyr & $0.17 \pm 0.01$ & $0.23 \pm 0.02^{\mathrm{a}}$ & $0.31 \pm 0.01^{\mathrm{b}, \mathrm{d}}$ & $0.63 \pm 0.03^{b, d, f}$ \\
\hline Phe & $0.14 \pm 0.01$ & $0.23 \pm 0.01^{b}$ & $0.22 \pm 0.01^{\mathrm{b}}$ & $0.34 \pm 0.01^{\mathrm{b}, \mathrm{d}, \mathrm{f}}$ \\
\hline Trp & $0.02 \pm 0.00$ & $0.04 \pm 0.00^{\mathrm{a}}$ & $0.05 \pm 0.00^{\mathrm{b}, \mathrm{c}}$ & $0.12 \pm 0.01^{\mathrm{b}, \mathrm{d}, \mathrm{f}}$ \\
\hline Lys & $0.76 \pm 0.04$ & $0.78 \pm 0.05$ & $0.93 \pm 0.04^{\mathrm{a}, \mathrm{d}}$ & $1.52 \pm 0.10^{\mathrm{b}, \mathrm{d}, \mathrm{f}}$ \\
\hline $\mathrm{His}$ & $0.27 \pm 0.01$ & $0.27 \pm 0.01$ & $0.29 \pm 0.01^{\mathrm{c}}$ & $0.35 \pm 0.02^{\mathrm{b}, \mathrm{d}, \mathrm{f}}$ \\
\hline Arg & $0.24 \pm 0.03$ & $0.33 \pm 0.02$ & $0.33 \pm 0.02$ & $0.38 \pm 0.02^{\mathrm{b}, \mathrm{d}, \mathrm{f}}$ \\
\hline
\end{tabular}

Values are means $\pm \mathrm{SE}$ for five observations. A statistically significant difference is shown by the superimposed letters: ${ }^{\mathrm{a}} p<0.05 \mathrm{vs}$. unperfused, ${ }^{\mathrm{b}} p<0.01 \mathrm{vs}$. unperfused, ${ }^{\mathrm{c}} p<0.05 v s .0 \times,{ }^{\mathrm{d}} p<0.01 v s .0 \times,{ }^{\mathrm{e}} p<0.05 v s .1 \times,{ }^{\mathrm{f}} p<0.01 v s .1 \times$. 
Table 3. Comparison between total uptake from perfusate and total increase in intracellular pool during the perfusion of amino acids at 5 times normal plasma levels $(5 \times)$.

\begin{tabular}{|c|c|c|c|}
\hline & $\begin{array}{l}\text { Total uptake } \\
\text { from perfusate } \\
\quad(\mu \mathrm{mol})\end{array}$ & & $\begin{array}{c}\text { Total increase } \\
\text { in intracellular pool } \\
(\mu \mathrm{mol})\end{array}$ \\
\hline Asp & 2.8 & $>$ & -1.9 \\
\hline Thr & 14.4 & $<$ & 18.0 \\
\hline Ser & 10.4 & $>$ & 4.5 \\
\hline Asn & 4.8 & $<$ & 5.4 \\
\hline Glu & 18.6 & $\gg$ & -32.1 \\
\hline Gln & -10.9 & $\ll$ & 6.1 \\
\hline Pro & 4.7 & $<$ & 9.6 \\
\hline Gly & -2.6 & $>$ & -3.3 \\
\hline Ala & 12.3 & $\ll$ & 69.3 \\
\hline Val & 11.4 & $>$ & 8.4 \\
\hline Met & 1.1 & $<$ & 2.1 \\
\hline Ile & 7.1 & $>$ & 3.0 \\
\hline Leu & 8.9 & $>$ & 6.1 \\
\hline Tyr & 7.2 & $<$ & 10.8 \\
\hline Phe & 0.4 & $<$ & 4.7 \\
\hline $\operatorname{Trp}$ & 1.5 & $<$ & 2.3 \\
\hline Lys & 14.0 & $<$ & 17.8 \\
\hline His & 0.0 & $<$ & 1.9 \\
\hline Arg & -1.6 & $<$ & 3.3 \\
\hline
\end{tabular}

Values were calculated as described in MATERIALs AND Methods. (-) in the left column means release into perfusate; $(-)$ in the right column means decrease in intracellular pool.

their perfusate levels (Fig. 1). However, in the intracellular pool of muscle, the level of alanine increased in all groups whereas that of glutamine decreased in $0 \times$ and $1 \times$ groups and increased in the $5 \times$ group only. As for the other amino acids, their tissue levels gradually increased with the increase in their perfusate levels.

To clarify quantitatively the relationship between the flows of amino acids and their metabolism in the tissue, in the $5 \times$ group, we tried to calculate and compare the total amounts of amino acid uptake from the perfusate with those of the increase in the intracellular pool (Table 3). As to the amino acids which are not metabolized in skeletal muscle, the amounts taken up by muscle should be equal to the increase in the intracellular pool. However, the increased amounts in the intracellular pool were slightly higher than those disappearing from the perfusate (threonine, asparagine, proline, methionine, tyrosine, phenylalanine, tryptophan, lysine, histidine and arginine). These net increases in the intracellular pool may reflect the net catabolism of muscle proteins even in the presence of excess plasma

Vol. 30, No. 2, 1984 
amino acids. These amino acids belong to the group of "neither taken up nor released." Glutamate and aspartate decreased in the intracellular pool in spite of their uptake from the perfusate. As for valine, leucine, isoleucine and serine, the increased amounts in the intracellular pool were less than those taken up from the perfusate. This strongly supports the findings that these amino acids are metabolized in skeletal muscle. Glutamine increased in the intracellular pool and at the same time was released from the tissue. On the other hand, alanine increased in the intracellular pool to a larger extent than the amount taken up from perfusate. It was considered that alanine was synthesized de novo much more than glutamine under our experimental conditions.

\section{DISCUSSION}

Although our system of hindquarter perfusion contained no humoral factors in the perfusate, e.g., metabolites, hormones, etc., it was proved to be a system comparable to muscle in vivo at least as regards the parameters we had measured (Table 1).

The results of the present study indicate that the flow of amino acids into and out of skeletal muscle responds differently to the changes in the amino acid levels of the perfusate. In $0 \times$ and $1 \times$ groups, most of the amino acids except glutamate and aspartate, were released gradually during the $2 \mathrm{~h}$ perfusion period. This was not due to their leakage from the intracellular pools of muscle but due to muscle protein degradation, because the amounts of free amino acids in muscle did not decrease during the $2 \mathrm{~h}$ (Table 2). On the other hand, in the $5 \times$ group, the flows of amino acids were variable depending on the metabolic properties of the latter. The results suggested that there were four groups of amino acids characterized by flow into or out of skeletal muscle in response to changes in their perfusate levels. As for the liver, Bloxam showed a similar result to ours showing that the amino acids in the perfusate were taken up or released in different ways, and proposed three kinds of

Table 4. Complementary role of muscle and liver in the regulation of plasma amino acid levels.

\begin{tabular}{lll}
\hline \multicolumn{1}{c}{ Direction } & \multicolumn{1}{c}{ Muscle } & \multicolumn{1}{c}{ Liver $^{\mathrm{a}}$} \\
\hline Uptake only & Glu, Asp & Glu, Asp, Ala, Ser, Arg \\
Release only & Ala, Gln, Gly & Val, Leu, Ile \\
Uptake and release & Val, Leu, Ile, Ser, (Thr) & $\begin{array}{l}\text { Met, Tyr, Phe, Trp, Pro, } \\
\text { His, Lys, Thr, Gly }\end{array}$ \\
$\begin{array}{l}\text { No change } \\
\text { (in high concn.) }\end{array}$ & Tyr, Phe, Trp, His, Met, & \\
\hline
\end{tabular}

${ }^{\mathrm{a}}$ Results of liver perfusion were cited from Bloxam(2). 
amino acid groups according to the characteristics of their flows (2). Comparing our results with his, we can model a complementary relationship of amino acid flows between skeletal muscle and the liver as shown in Table 4. Glutamate and aspartate were always taken up by both organs irrespective of their levels in the perfusate, suggesting that these neurotoxic amino acids are rapidly removed from the bloodstream by both organs. Alanine was always taken up by the liver but released from muscle, and this flow from muscle to the liver supported the metabolic significance of the glucose-alanine cycle under fasting conditions (11). As regards glutamine, there are no available data for the liver, but this amino acid was always released from muscle like alanine. Glutamine, which is released from muscle as another major nitrogen carrier, is known to be transported to the kidney in the acidotic state and to the small intestine in the normal state(12). Our finding that alanine was synthesized to a higher extent than glutamine under these conditions did not agree with that of Ruderman and Berger (13). This discrepancy seems to be due to the difference in nutritional conditions, i.e., fed or overnight fasting states. The above workers mentioned that formation of alanine by skeletal muscle increased with fasting, whereas glutamine formation was constant. Branched-chain amino acids were always released from the liver under fasting conditions, but the directions of their flow across muscle were regulated depending on their levels in the perfusate. This strongly suggests that the plasma levels of the branched-chain amino acids are regulated mainly by muscle, and not by the liver. Although the flow of serine was also regulated by muscle, this amino acid was always taken up by the liver. The flow of threonine can be regulated by both muscle and liver, the extent of which is, however, not as great as in the case of serine. From the findings that this amino acid was not metabolized in skeletal muscle (Table 3), it is obscure whether muscle actually regulates the plasma level of threonine or not. Glycine was always released from muscle and the direction of its flow was regulated by the liver. The flows of other amino acids were not influenced by muscle even at high levels in the perfusate. Therefore, plasma levels of these amino acids are presumably regulated exclusively by the liver. From the above considerations, it was concluded that skeletal muscle and liver play complementary metabolic roles in regulating plasma amino acid levels. Similar perspectives have been presented by Aikawa et al. employing the arterio-venous difference method(14). However, they could only show the flows of quantitatively major amino acids, e.g., alanine, glutamine, glycine or serine, because the arterio-venous differences in essential amino acid levels were so small. Furthermore, they did not show the response of the organs studied to changes in plasma amino acid levels. On the other hand, we were able to confirm the regulatory role of skeletal muscle in response to the plasma levels of all amino acids including essential ones.

In the present study, we investigated the effects of amino acid levels in the perfusate on their flows across muscle. The perfusate in our study lacked many nutritional and hormonal factors, e.g., fatty acids, ketone bodies, insulin, glucocorticoids, etc., which should be present in normal blood and would influence plasma 
amino acid levels. It is necessary to investigate further how nutritional and hormonal factors affect amino acid levels in plasma.

\section{REFERENCES}

1) Christensen, H. N. (1982): Interorgan amino acid nutrition. Physiol. Rev., 62, 1193 1233.

2) Bloxam, D. L. (1971): Nutritional aspects of amino acid metabolism. 1. A rat liver perfusion method for the study of amino acid metabolism. Br. J. Nutr., 26, 393-422.

3) Ebisawa, H., Yamamoto, S., Yamamoto, T., Kishi, K., and Inoue, G. (1983): Effects of muscle amino acid metabolism on plasma free amino acids in normal and proteindeficient adult rats. Nutr. Rep. Intern., 27, 485-498.

4) Yagasaki, K., and Kametaka, M. (1977): Triglyceride release and fatty acid oxidation by the perfused liver of rats fed a low protein diet. Agric. Biol. Chem., 41, 1435-1441.

5) Ruderman, N. B., Houghton, C. R. S., and Hems, R. (1971): Evaluation of the isolated perfused rat hindquarter for the study of muscle metabolism. Biochem. J., 124, 639-651.

6) Jefferson, L. S. (1975): A technique for perfusion of an isolated preparation of rat hemicorpus. Methods Enzymol., 39, 73-82.

7) Lamprecht, W., Stein, P., Heinz, F., and Weisser, H. (1974): Creatine phosphate, in Methods of Enzymatic Analysis, 2nd English Ed., ed. by Bergmeyer, H. U., Academic Press, Inc., New York and London, pp. 1777-1781.

8) Gutmann, I., and Wahlefeld, A. W. (1974): L-(+)-Lactate. Determination with lactate dehydrogenase and NAD, in Methods of Enzymatic Analysis, 2nd English Ed., ed. by Bergmeyer H. U., Academic Press, Inc., New York and London, pp. 1464-1468.

9) Snedecor, G. W., and Cochran, W. G. (1967): Statistical Methods, 6th Ed., The Iowa State University Press, Ames, Iowa, Chap. 4.

10) Ward, L. C., and Buttery P. J. (1979): The kinetics of myofibrillar protein breakdown in perfused rat skeletal muscle. Biochim. Biophys. Acta, 587, 415-423.

11) Felig, P. (1975): Amino acid metabolism in man. Annu. Rev. Biochem., 44, 933-955.

12) Lund, P. (1980): Glutamine metabolism in the rat. FEBS Lett., 117, K86-K92.

13) Ruderman, N. B., and Berger, M. (1974): The formation of glutamine and alanine in skeletal muscle. J. Biol. Chem., 249, 5500-5506.

14) Aikawa, T., Matsutaka, H., Yamamoto, H., Okuda, T., Ishikawa, E., Kawano, T., and Matsumura, E. (1973): Gluconeogenesis and amino acid metabolism. II. Inter-organal relations and roles of glutamine and alanine in the amino acid metabolism of fasted rats. J. Biochem., 74, 1003-1017. 